\title{
Sulforaphane Prevents Angiotensin II-Induced Testicular Cell Death via Activation of NRF2
}

\author{
Yonggang Wang, ${ }^{1,2}$ Hao Wu, ${ }^{3}$ Ying Xin, ${ }^{2,4}$ Yang Bai, ${ }^{2,5}$ Lili Kong, ${ }^{2,6}$ Yi Tan, ${ }^{2,7}$ \\ Feng Liu, ${ }^{8}$ and Lu Cai ${ }^{2,7}$ \\ ${ }^{1}$ Department of Urology, China-Japan Union Hospital of Jilin University, 126 Xiantai St, Changchun, Jilin 130033, China \\ ${ }^{2}$ Pediatric Research Institute, Department of Pediatrics, Wendy L. Novak Diabetes Care Center, University of Louisville, \\ 570 S Preston St, Louisville, KY 40202, USA \\ ${ }^{3}$ Department of Nephrology, The Second Hospital of Jilin University, 218 Ziqiang St, Changchun, Jilin 130041, China \\ ${ }^{4}$ The Key Laboratory of Pathobiology, Ministry of Education, The Norman Bethune Medical College, Jilin University, \\ Changchun, Jilin 130021, China \\ ${ }^{5}$ Cardiovascular Center, The First Hospital of Jilin University, 71 Xinmin St, Changchun, Jilin 130021, China \\ ${ }^{6}$ Department of Nephrology, The First Hospital of Jilin University, 71 Xinmin St, Changchun, Jilin 130021, China \\ ${ }^{7}$ Chinese-American Research Institute for Diabetic Complications, School of Pharmaceutical Science, Wenzhou Medical University, \\ Wenzhou, Zhejiang, China \\ ${ }^{8}$ Department of Nephrology, China-Japan Union Hospital of Jilin University, Changchun, China, 126 Xiantai St, \\ Changchun, Jilin 130033, China
}

\begin{abstract}
Correspondence should be addressed to Hao Wu; wuhaobaha@jlu.edu.cn, Feng Liu; jdliufeng@163.com, and Lu Cai; 10cai001@louisville.edu
\end{abstract}

Received 31 July 2016; Revised 28 November 2016; Accepted 12 December 2016; Published 16 January 2017

Academic Editor: Christian Wigley

Copyright (C) 2017 Yonggang Wang et al. This is an open access article distributed under the Creative Commons Attribution License, which permits unrestricted use, distribution, and reproduction in any medium, provided the original work is properly cited.

Although angiotensin II (Ang II) was reported to facilitate sperm motility and intratesticular sperm transport, recent findings shed light on the efficacy of Ang II in stimulating inflammatory events in testicular peritubular cells, effect of which may play a role in male infertility. It is still unknown whether Ang II can induce testicular apoptotic cell death, which may be a more direct action of Ang II in male infertility. Therefore, the present study aims to determine whether Ang II can induce testicular apoptotic cell death and whether this action can be prevented by sulforaphane (SFN) via activating nuclear factor (erythroid-derived 2)-like 2 (NRF2), the governor of antioxidant-redox signalling. Eight-week-old male C57BL/6J wild type (WT) and Nrf2 gene knockout mice were treated with Ang II, in the presence or absence of SFN. In WT mice, SFN activated testicular NRF2 expression and function, along with a marked attenuation in Ang II-induced testicular oxidative stress, inflammation, endoplasmic reticulum stress, and apoptotic cell death. Deletion of the Nrf2 gene led to a complete abolishment of these efficacies of SFN. The present study indicated that Ang II may result in testicular apoptotic cell death, which can be prevented by SFN via the activation of NRF2.

\section{Introduction}

Infertility affects 6.1 million US couples, representing $10 \%$ of reproductive-age adults and $15 \%$ of all couples trying to conceive. Half of the time, infertility is the result of an abnormal semen analysis or other male factors [1]. Therefore, there remains an urgent need to identify novel targets and develop novel medicines to prevent male infertility.

Although angiotensin II (Ang II) exerts significant functions in multiple organs and systems [2-4], little is known about Ang II action in male infertility. Both Ang II type 1 and type 2 receptors are found in testis [5], indicating that Ang II may have an important impact on male reproductive function. Previous findings showed that Ang II facilitated human sperm motility $[5,6]$. Hence, Ang II may play a beneficial role in male fertility. However, a recent study by Welter et al. showed that Ang II also generated inflammatory events in testicular peritubular cells, in addition to the cell contraction [7]. Consequently, the induction of inflammation by Ang II may exert negative effects in male fertility. 
Ang II is found to induce oxidative stress [8, 9]. Previously we reported that Ang II played a critical role in cardiac alcohol-induced cardiac nitrosative damage, cell death, remodelling, and cardiomyopathy [10]. We also found that Ang II activated NADPH oxidase-mediated nitrosative damage to induce pulmonary fibrosis [11]. Notably, oxidative stress contributes to testicular apoptotic cell death [12-16]. Oxidative stress is also known to induce endoplasmic reticulum (ER) stress $[17,18]$, which has also been demonstrated to play an important role in testicular apoptotic cell death [19-23]. Moreover, a crosstalk has been established between oxidative stress and ER stress [24, 25]. NRF2 controls cellular defence mechanisms against oxidative stress [26] by turning on the transcription of antioxidant genes, such as $\mathrm{Hol}$ and Nqo1 [27, 28]. Notably, NRF2 plays a critical role in prevention of male infertility, since Nrf2-null male mice developed infertility in an age-dependent manner [29]. Therefore, NRF2 activation may be a promising strategy to ameliorate Ang IIinduced testicular apoptotic cell death.

SFN is a potent activator of NRF2 [30, 31]. We have demonstrated the critical role of NRF2 in SFN protection against diabetes-induced testicular apoptosis [32], diabetic nephropathy [31], and diabetic cardiomyopathy [33]. However, it is unclear whether or how much NRF2 may contribute to the effect of SFN on Ang II-induced testicular injury. The present study aims to answer the following questions: (1) does Ang II induce testicular apoptotic cell death? (2) Does SFN have protective effect on Ang II-induced testicular injury? (3) Does NRF2 contribute to the protective effect of SFN? And if so, how much? To these ends, Nrf2-null mice and their WT controls were subjected to Ang II, in the presence or absence of SFN.

\section{Methods}

2.1. Animal Treatment. Nrf2-null (Nrf2 $\left.{ }^{-/-}\right)$mice with C57BL/ $6 \mathrm{~J}$ background (WT) were obtained through breeding of homozygote $\left(\mathrm{Nrf2} 2^{-/-}\right)$with heterozygote $\left(\mathrm{Nrf2} 2^{+/-}\right)$following the mating system suggested by Jackson Laboratory (Bar Harbor, ME, USA). C57BL/6J male mice $\left(\mathrm{Nrf2} 2^{+/+}\right)$were also purchased from the Jackson Laboratory. All mice were housed in University of Louisville Research Resources Center at $22^{\circ} \mathrm{C}$, on a $12 \mathrm{~h}$ light-dark cycle, with free access to standard rodent feed and tap water. The Institutional Animal Care and Use Committee at University of Louisville approved all experimental procedures for these animals, and all procedures complied with the Guide for the Care and Use of Laboratory Animals by the US National Institutes of Health (2011, eighth edition). To test the preventive effect of SFN on Ang II-induced testis injury, as well as the role of NRF2 in SFN action, eight-week-old WT or Nrf2-null mice were randomized into the following groups, respectively $(n=5$ per group): control (Ctrl), SFN-treated control (Ctrl/SFN), Ang II-treated mice (Ang II), and mice treated with Ang II and SFN in combination (Ang II/SFN). Mice received subcutaneous injections of Ang II (Sigma-Aldrich, St Louis, MO, USA, $0.5 \mathrm{mg} / \mathrm{Kg}$ ) every other day for two months and SFN (Sigma-Aldrich, St Louis, MO, USA, $0.5 \mathrm{mg} / \mathrm{Kg}$ ) five days each week for three months as previously described
[11, 31, 32, 34, 35]. Mice were then killed with their testis and caudae epididymis harvested for analysis. Experimenters of this study were blind to group assignment and outcome assessment.

2.2. Sperm Density Assessment. Caudae epididymis from each mouse was placed in $2 \mathrm{~mL}$ Earle's balanced salt solution (Sigma-Aldrich, St. Louis, MO, USA) supplemented with $0.1 \%$ bovine serum albumin (Sigma-Aldrich). The epididymis was gently teased with a bent needle to release spermatozoa under observation through a stereomicroscope (Olympus). Sperm density was assessed with a haemocytometer and was presented by spermatozoa count per epididymis [36, 37].

2.3. Western Blot Analysis. Western blot was performed using testis tissue as described in our previous study [38]. The primary antibodies included anti-3-NT (Millipore, Temecula, CA, USA; 1:1,000), anti-4-HNE (Alpha Diagnostic, San Antonio, TX, USA; 1:3,000), anti-Actin (Santa Cruz Biotechnology, Dallas, TX, USA, 1:2,000), anti-ATF4 (Cell Signaling Technology, Danvers, MA, USA, 1:1000), antiBax (Cell Signaling Technology, 1:1000), anti-Bcl-2 (Santa Cruz Biotechnology, $1: 2,000$ ), anti-caspase-3 (Cell Signaling Technology, 1:1000), anti-caspase-8 (Cell Signaling Technology, $1: 1000$ ), anti-caspase-12 (Cell Signaling Technology, 1:1000), anti-CHOP (Cell Signaling Technology, 1:1000), anti-Histone H3 (Santa Cruz Biotechnology; 1:500), antiIL-6 (Cell Signaling Technology, 1:1000), anti-NRF2 (Santa Cruz Biotechnology, $1: 1000)$, anti-TNF- $\alpha$ (Abcam, 1:2,000), and anti-VCAM-1 (Santa Cruz Biotechnology, 1: 500)

2.4. Quantitative Reverse Transcription PCR ( $q P C R)$. qPCR was performed as described in our previous studies [39, 40]. Primers for $\mathrm{Hol}$ and $\mathrm{Nqol}$ were purchased from Life Technologies (Grand Island, NY, USA).

2.5. Histological, Immunohistochemical Staining and Terminal Deoxynucleotidyl Transferase-Mediated dUTP Nick End Labeling (TUNEL) Assay. Testis tissues were fixed immediately in $10 \%$ buffered formalin solution after harvesting and were embedded in paraffin and sectioned into $5 \mu \mathrm{m}$ thick sections onto glass slides. The sections were processed for hematoxylin and eosin ( $\mathrm{H} \& \mathrm{E})$ staining. To test the status of testicular cell apoptosis, TUNEL assay was performed as previously described [32].

2.6. Isolation of Nuclei. Testicular nuclei were isolated using a nuclei isolation kit (Sigma-Aldrich) as previously described [41]. Briefly, testis tissue (30 mg) from each mouse was homogenised for $45 \mathrm{~s}$ in $150 \mu \mathrm{L}$ of cold lysis buffer containing $0.5 \mu \mathrm{L}$ of dithiothreitol (DTT) and $0.1 \%$ Triton X-100. After that, $300 \mu \mathrm{L}$ of cold $1.8 \mathrm{~mol} / \mathrm{L}$ cushion solution (Sucrose cushion solution: sucrose cushion buffer: DTT $=900: 100: 1)$ was added to the lysis solution. The mixture was transferred to a new tube preloaded with $150 \mu \mathrm{L}$ of $1.8 \mathrm{~mol} / \mathrm{L}$ sucrose cushion solution followed by centrifugation at $30,000 \mathrm{~g}$ for $45 \mathrm{~min}$. The supernatant fraction, containing cytosolic components, was aspirated and the nuclei were visible as a thin pellet at the bottom of the tube. 


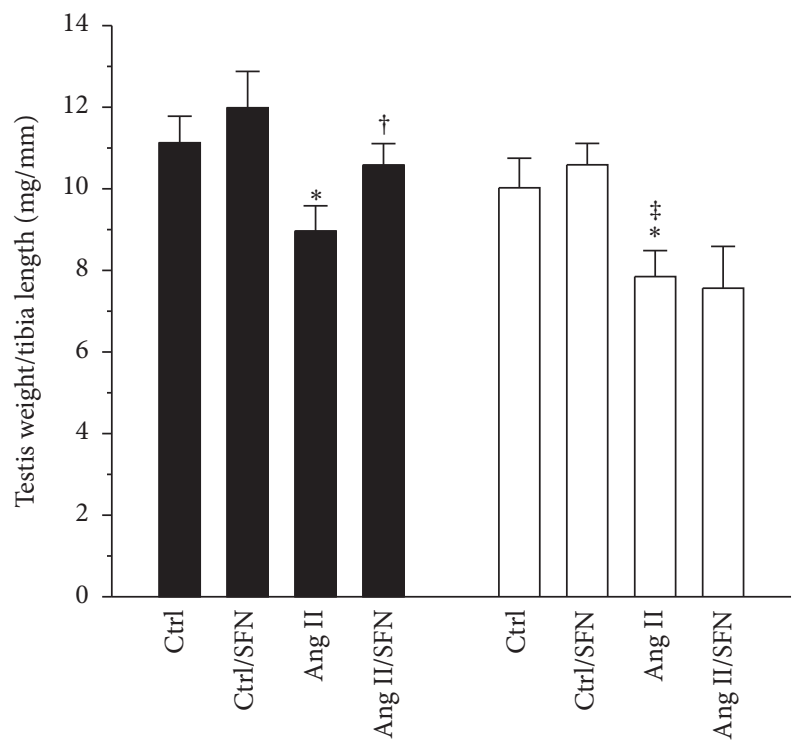

WT
Nrf2-null
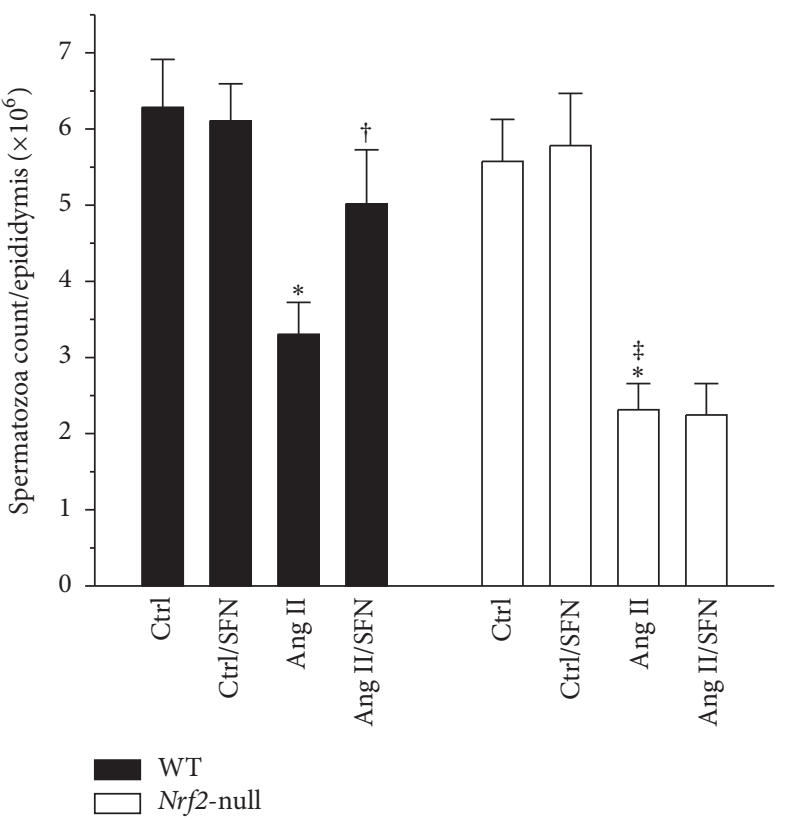

(b) (a)

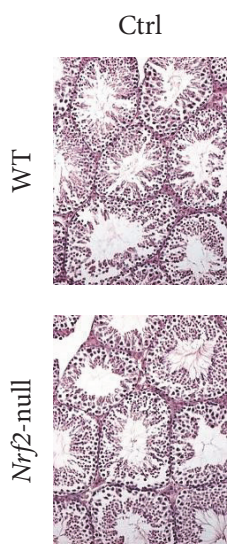

\begin{abstract}
$\mathrm{Ctrl} / \mathrm{SFN}$
\end{abstract}
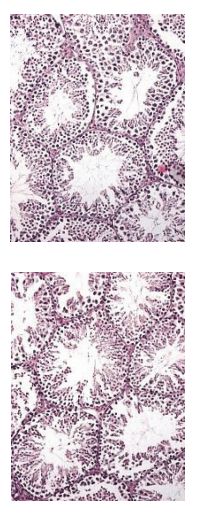

Ang II
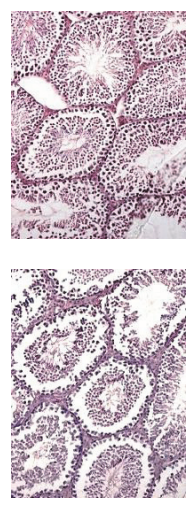

Ang II/SFN
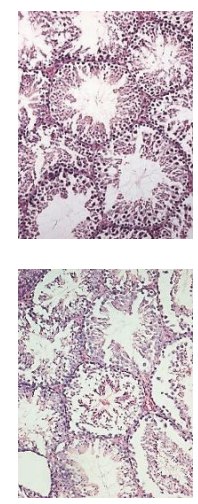

(c)

Figure 1: Deletion of the Nrf2 gene completely abolished SFN protection against Ang II-induced decrease in testicular weight and spermatozoa count. (a) Testis weight to tibia length ratio was calculated after WT and Nrf2-null mice were killed. (b) Sperm density assessment was done by performing spermatozoa count. (c) H\&E staining was conducted for observation of morphological change. Data are presented as means $\pm \mathrm{SD}(n=5) .{ }^{*} p<0.05$ versus $\mathrm{Ctrl} ;{ }^{\dagger} p<0.05$ versus Ang II. ${ }^{\ddagger} p<0.05$ versus WT mice treated with Ang II.

2.7. Statistical Analysis. Five mice per group were studied. The measurements for each group were summarised as means \pm SD. Image Quant 5.2 (GE Healthcare Bio-Sciences, Pittsburgh, PA, USA) was used to analyse Western blots. One-way ANOVA was performed for comparisons among different groups, followed by post hoc pairwise comparisons using Tukey's test with Origin 8.6 data analysis and graphing software Lab (OriginLab, Northampton, MA, USA). Differences were significant if $p<0.05$.

\section{Results}

3.1. Deletion of the Nrf2 Gene Completely Abolished SFN Protection against Ang II-Induced Decrease in Testicular Weight and Spermatozoa Count. Nrf2-null mice suffered from a more significant decrease in Ang II-induced testicular weight (Figure 1(a)) and spermatozoa count (Figure 1(b)). WT mice, but not Nrf2-null mice, benefited from SFN protection against these injuries (Figures 1(a) and 1(b)). H\&E staining showed no significant changes between the groups (Figure 1(c)). These results implicate that testicular apoptotic cell death may play an important role in Ang II-induced testicular weight loss, and NRF2 is required in the protective effect of SFN.

3.2. SFN Alleviated Ang II-Induced Testicular Apoptotic Cell Death through the Activation of NRF2. Ang II resulted in a marked increase in the number of apoptotic cells in the testis of WT mice (Figure 2(a), left panel). Moreover, this effect of Ang II was more prominent in Nrf2-null mice (Figure 2(a), right panel). Mitochondrial pathway was further evaluated by determining the protein levels of Bax, Bcl-2, and caspase-3. 

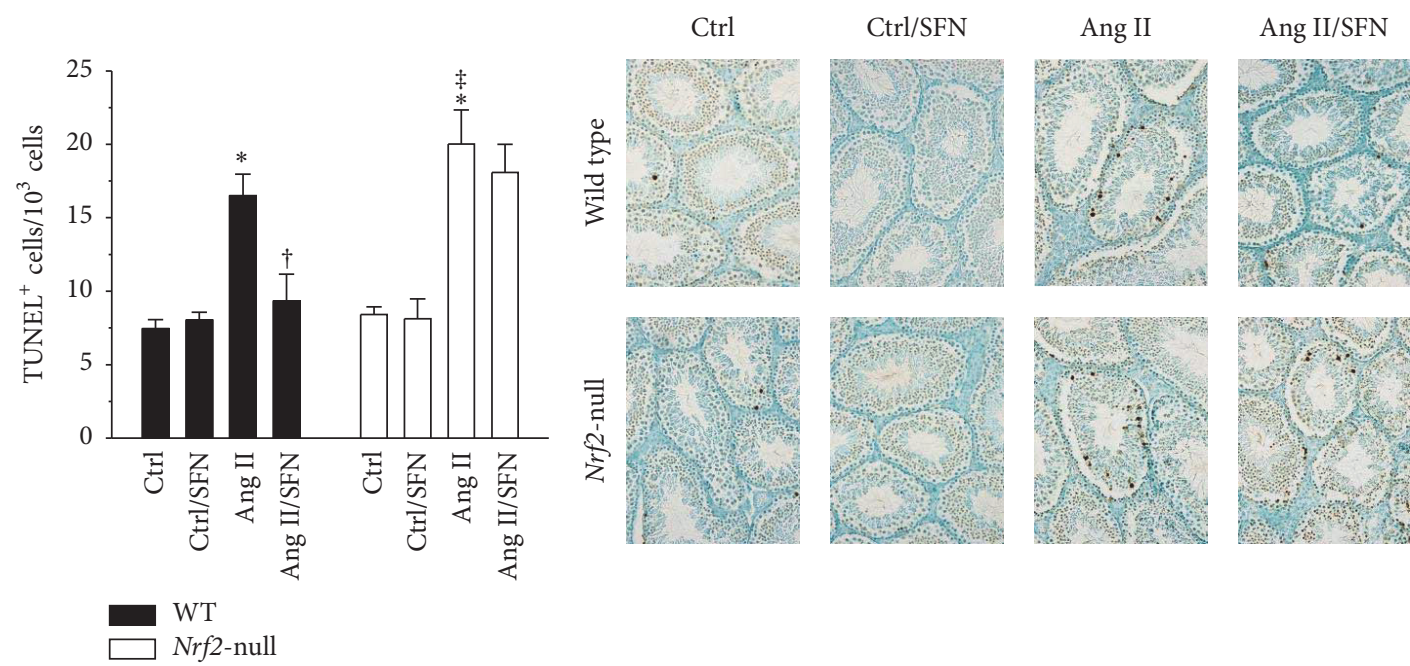

(a)
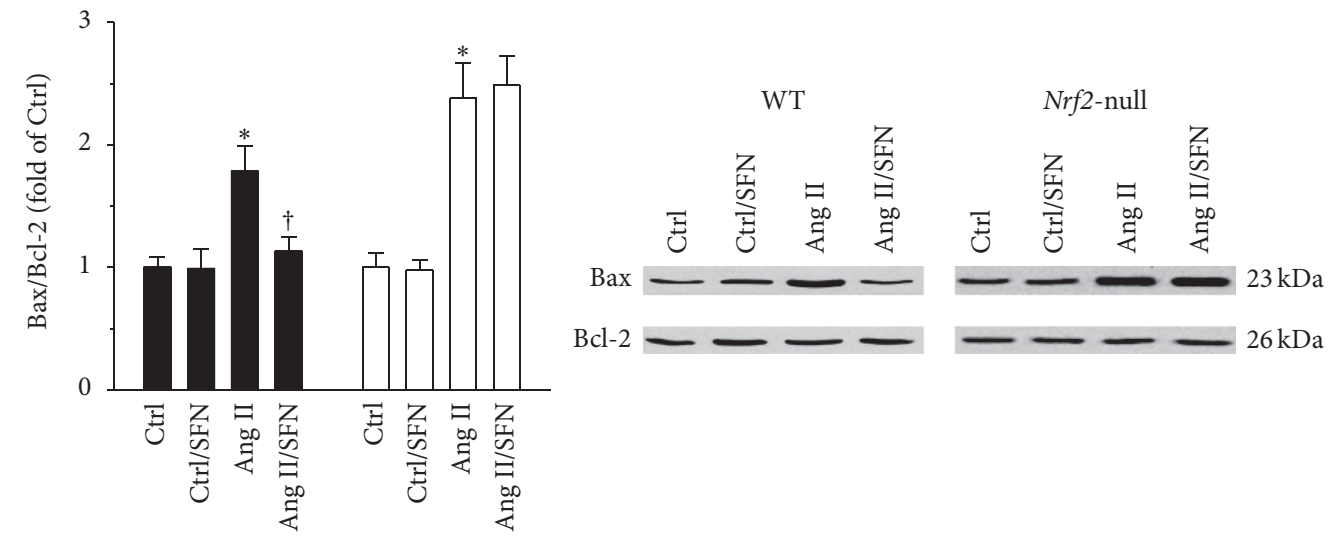

WT

Nrf2-null

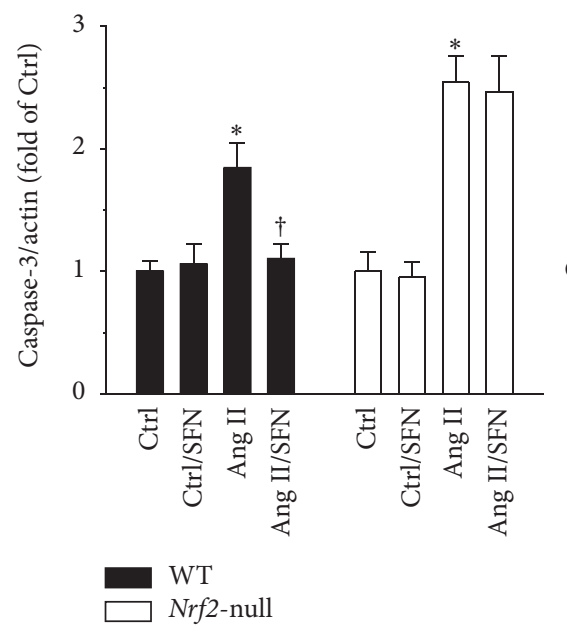

(b)

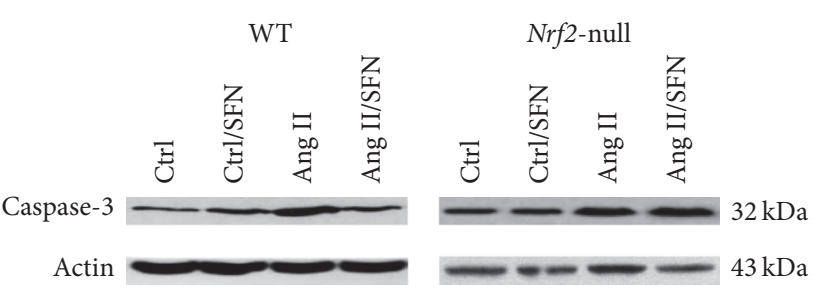

(c)

FIgURE 2: SFN alleviated Ang II-induced testicular apoptotic cell death through the activation of NRF2. (a) TUNEL staining was performed to evaluate the effect of SFN on Ang II-induced testicular apoptotic cell death. Mitochondrial pathway was further evaluated by determining (b) the ratio of Bax to Bcl-2 and (c) the protein level of Caspase-3. For (b) and (c), data were normalised by respective Ctrl and presented as means $\pm \mathrm{SD}(n=5) .{ }^{*} p<0.05$ versus Ctrl; ${ }^{\dagger} p<0.05$ versus Ang II; ${ }^{\ddagger} p<0.05$ versus WT mice treated with Ang II. 
Ang II produced a significant increase in the ratio of Bax to $\mathrm{Bcl}-2$ (Figure 2(b)) and caspase-3 protein (Figure 2(c)). SFN prevented these effects of Ang II in WT mice (Figures 2(a)-2(c), left panels). However, deletion of the Nrf2 gene abrogated all these protective effects of SFN (Figures 2(a)2(c), right panels).

3.3. ER Stress, But Not Receptor Cell Death Pathway, Was Involved in Ang II-Induced Testicular Injury. In the following studies, we defined whether or not ER stress and receptor cell death pathways were involved in Ang II-induced testicular injury. In WT mice, Ang II increased the protein levels of ER stress pathway factors CHOP, caspase-12, BIP, and ATF4, effects of which were markedly prevented by SFN (Figures 3(a)-3(d), left panels). SFN failed to protect the testis from Ang II-induced ER stress in the absence of Nrf2 (Figures $3(\mathrm{a})-3(\mathrm{~d})$, right panels). No alteration in receptor cell death pathway by either Ang II or SFN was observed, as shown by TNF- $\alpha$ and caspase- 8 protein levels (Figures 3(e) and 3(f)).

3.4. NRF2 Was Required for SFN Amelioration of Ang IIInduced Testicular Inflammation. Given that Ang II stimulated testicular inflammation in vitro [7], we tested whether or not Ang II could cause testicular inflammation in vivo. Testicular IL- 6 and VCAM-1 proteins were elevated by Ang II, effects of which were significantly inhibited by SFN in WT mice, but not in Nrf2-null mice (Figures 4(a) and 4(b)).

3.5. NRF2 Played a Key Role in SFN Protection against Ang II-Induced Testicular Oxidative Stress. The status of testicular oxidative stress was evaluated since NRF2 is known to be the governor of cellular antioxidant activity. 3-NT and 4-HNE, the indicators of nitrosative and oxidative damage, were determined by Western blot. As shown in Figures 5(a) and 5(b), SFN almost completely prevented the Ang II-induced increase in testicular 3-NT and 4-HNE in WT mice (Figures 5(a) and 5(b), left panels), but not in Nrf2-null mice (Figures 5(a) and 5(b), right panels).

3.6. Nrf2 Gene Deletion Led to a Complete Loss of SFN Function in Activating Testicular Antioxidant Gene Transcription. NRF2 exerts its function through activation of the transcription of its downstream antioxidant genes. t-NRF2 and n-NRF2 proteins, as well as Hol and Nqo1 mRNAs, were determined. In WT mice, SFN significantly upregulated testicular t-NRF2 and n-NRF2 proteins (Figures 6(a) and 6(b), left panels), which were not detectable in Nrf2-null mice (Figures 6(a) and 6(b), right panels). Nrf2-null testis expressed lower Hol and Nqol mRNAs, as compared to WT testis (Figures 6(c) and 6(d)). Nrf2 gene deletion disabled the efficacy of SFN in increasing the transcription of $\mathrm{Hol}$ and Nqo1 (Figures 6(c) and 6(d)).

\section{Discussion}

The present study explored the protective effect of SFN on Ang II-induced testicular apoptotic cell death. By using Nrf2-null mice, NRF2 was found to play a critical role in this protection, since deletion of the Nrf2 gene led to a complete abolishment of SFN efficacies in the induction of NRF2 downstream targets and in the amelioration of Ang IIinduced testicular oxidative damage, ER stress, inflammation, and apoptotic cell death (Figure 7).

In the present study, Ang II increased Nrf2 expression and function in WT mice (Figures 6(a)-6(d), left panels). The administration of Ang II turned on NRF2 activation as an adaptive response to oxidative stress induced by Ang II. However, the mild increase of NRF2 by Ang II (Figures 6(a) and 6(b), left panels) was not sufficient to block Ang IIinduced testicular oxidative damage (Figures 5(a) and 5(b), left panels). The enhanced oxidative damage was almost completely prevented by SFN (Figures 5(a) and 5(b), left panels) via a more significant increase in Nrf2 expression and function (Figures 6(a)-6(d), left panels). Although the mild increase of NRF2 by Ang II (Figures 6(a) and 6(b), left panels) failed to block Ang II-induced oxidative damage (Figures 5(a) and 5(b), left panels), NRF2 still exerted protective effect, since Ang II produced more severe testicular injuries in Nrf2null mice, as compared to WT mice (Figures 1(a), 1(b), 2(a)2(c), 3(a)-3(d), 4(a), 4(b), 5(a) and 5(b)).

Ang II is reported to facilitate sperm motility $[5,6]$. However, in addition to this beneficial effect of Ang II, Ang II was also found to account for increased inflammation, according to a recent study by Welter et al. [7]. Therefore, a detrimental aspect of Ang II has been unveiled. Inflammation is positively associated with oxidative stress, which plays a key role in testicular cell death [42]. In line with this notion, we found an increase in these indices, along with reduced sperm density and testicular weight in Ang II-treated mice. Our study could be an in vivo support for the previous findings by Welter et al. [7]. Hormesis is defined by a biphasic dose response with specific quantitative features for the amplitude and width of the stimulation [43]. The induction of hormesis by low level stressor agents could rapidly upregulate adaptive processes to repair damage $[43,44]$. Therefore, we assume that the discrepancy between the present study and the study by Rossi et al. [6] could possibly be due to the dose difference of Ang II used between the two studies: Ang II concentration used in the previous publication [6] was $0.2 \mathrm{nM}$. However, we tested toxicological effect of Ang II at $0.5 \mathrm{mg} / \mathrm{kg}$ (roughly equal to $0.96 \mathrm{nM}, 4.8$-fold the value of $0.2 \mathrm{nM}$ ), for a long period in mice. In the latter, the toxicity was prominent, as shown by enhanced testicular oxidative damage (Figures 5(a) and 5(b)), inflammation (Figures 4(a) and 4(b)), ER stress (Figures 3(a)-3(d)), apoptosis (Figure 1(b); Figures 2(a)2(c)), and weight loss (Figure 1(a)). Secondly, results observed in vitro and in vivo may be different since, under the in vivo condition, systemic responses to chronic exposure of Ang II may generate a more complicate outcome in the testis. These important issues will be further explored in the future study.

NRF2 activators have been applied to clinical trials [45, 46]. Although a phase III study of bardoxolone methyl in the treatment of patients with diabetic nephropathy was terminated due to heart complications [47], NRF2 remains a promising drug target, as evidenced by the approval of dimethyl fumarate (also known as BG-12) for use in 


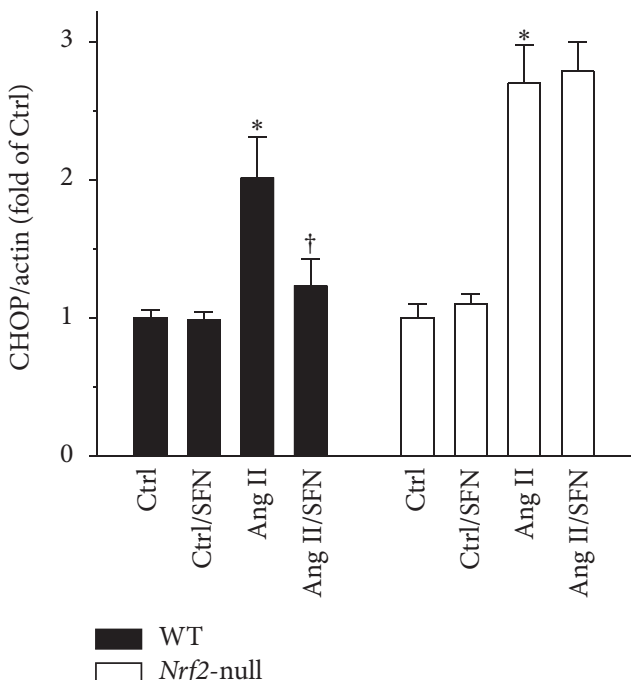

(a)

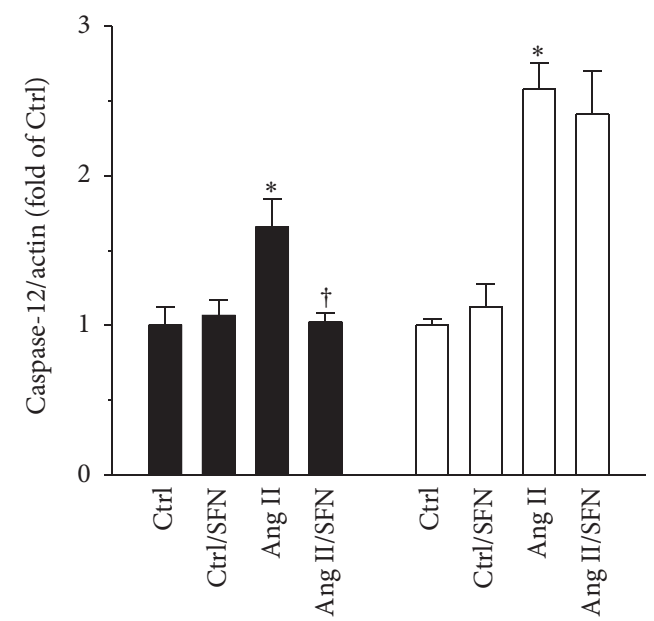

WT

$\square$ Nrf2-null

(b)

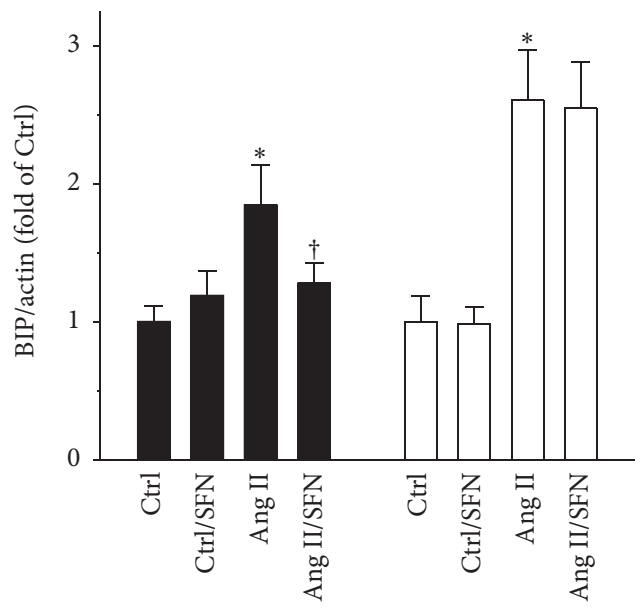

WT

$\square$ Nrf2-null
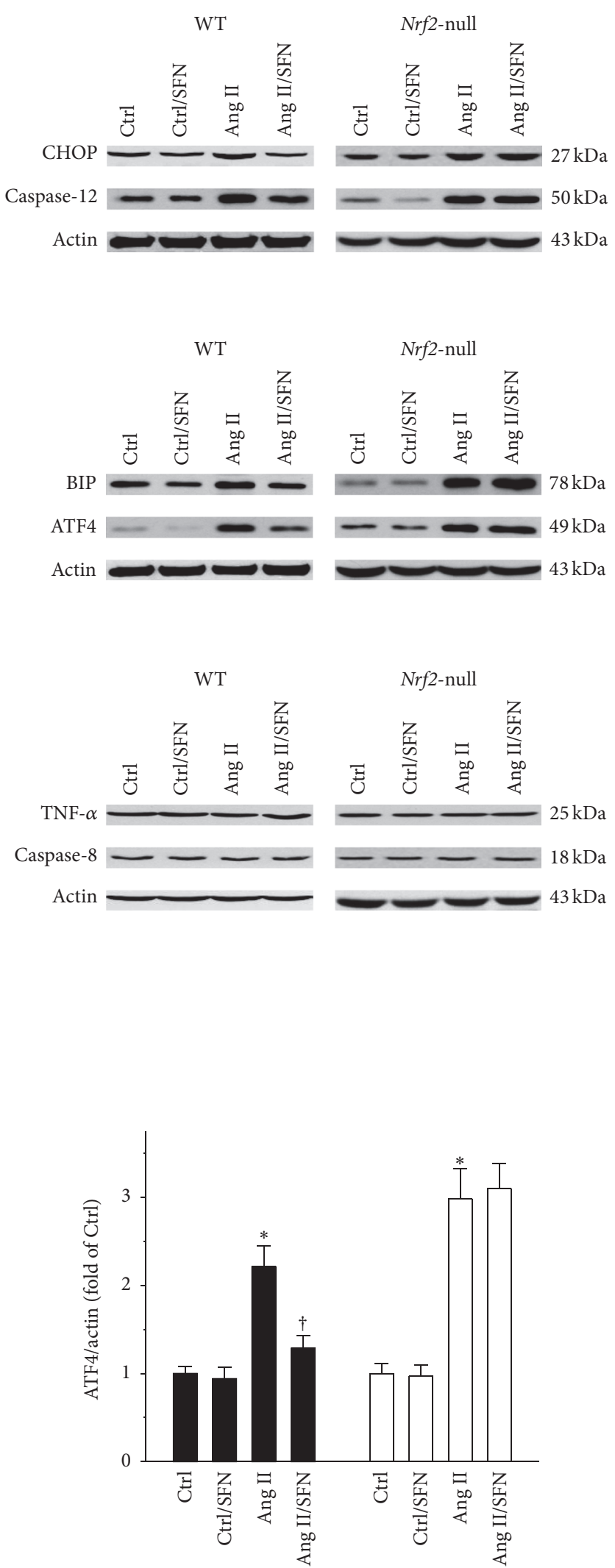

WT

$\square$ Nrf2-null

(d)

Figure 3: Continued. 


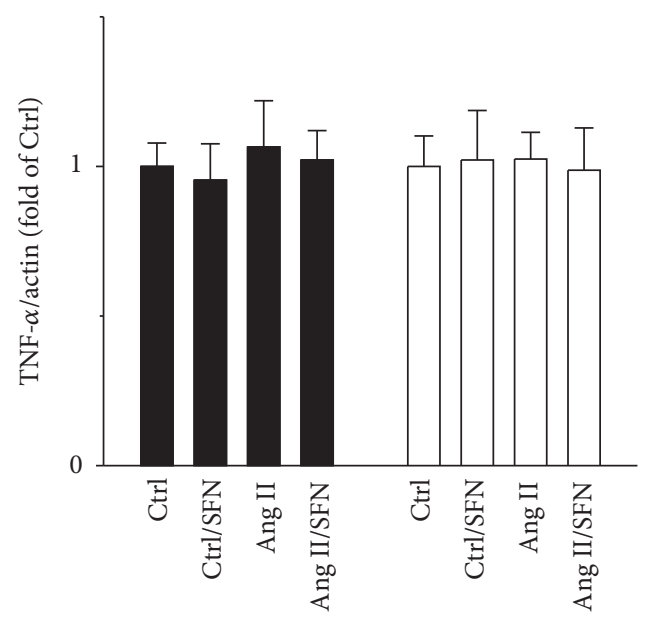

WT

Nrf2-null

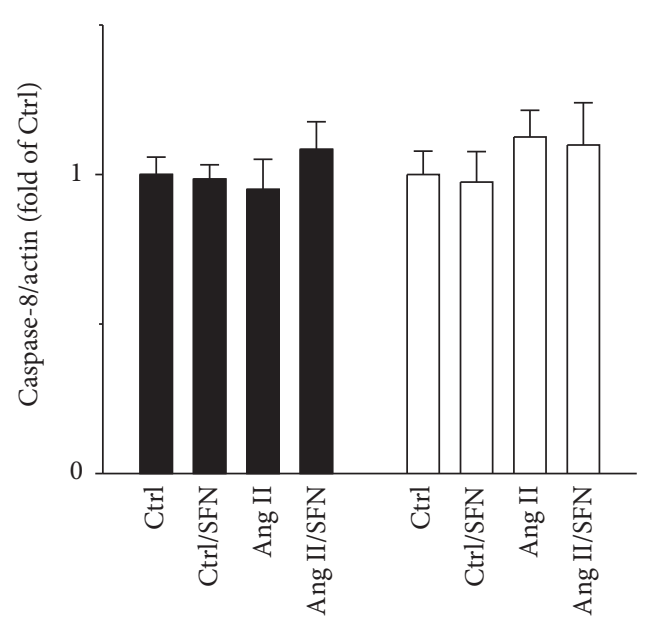

WT

Nrf2-null

(e)

(f)

FIGURE 3: ER stress, but not receptor cell death pathway, was involved in Ang II-induced testicular injury. ER stress was reflected by determining the protein levels of (a) CHOP, (b) caspase-12, (c) BIP, and (d) ATF4. Receptor cell death pathway was also evaluated by determining the protein levels of (e) TNF- $\alpha$ and (f) caspase- 8 . Data were normalised by respective Ctrl and presented as means \pm SD $(n=5)$. ${ }^{*} p<0.05$ versus $\mathrm{Ctrl} ;{ }^{\dagger} p<0.05$ versus Ang II.

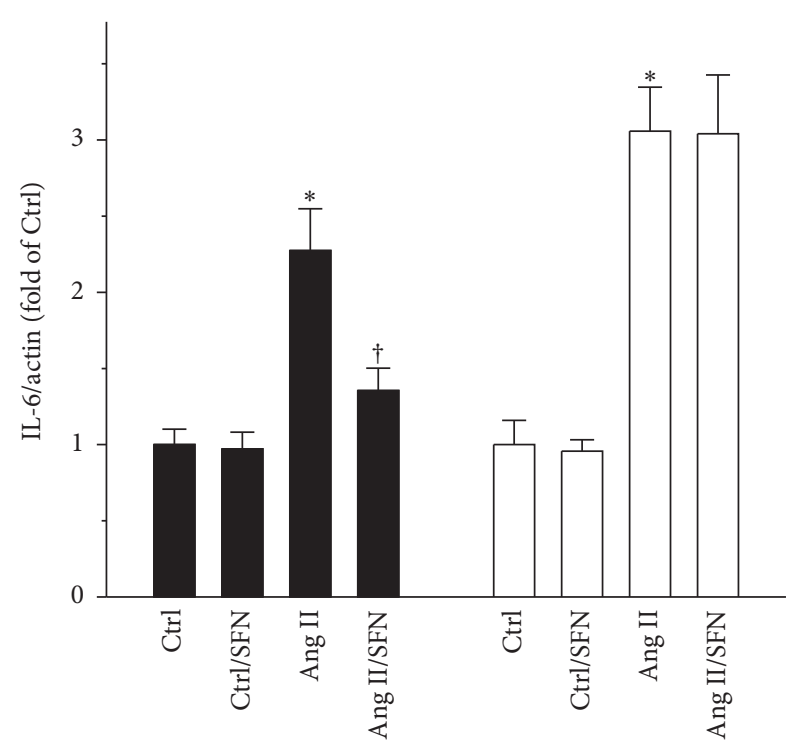

WT
$\square$ Nrf2-null

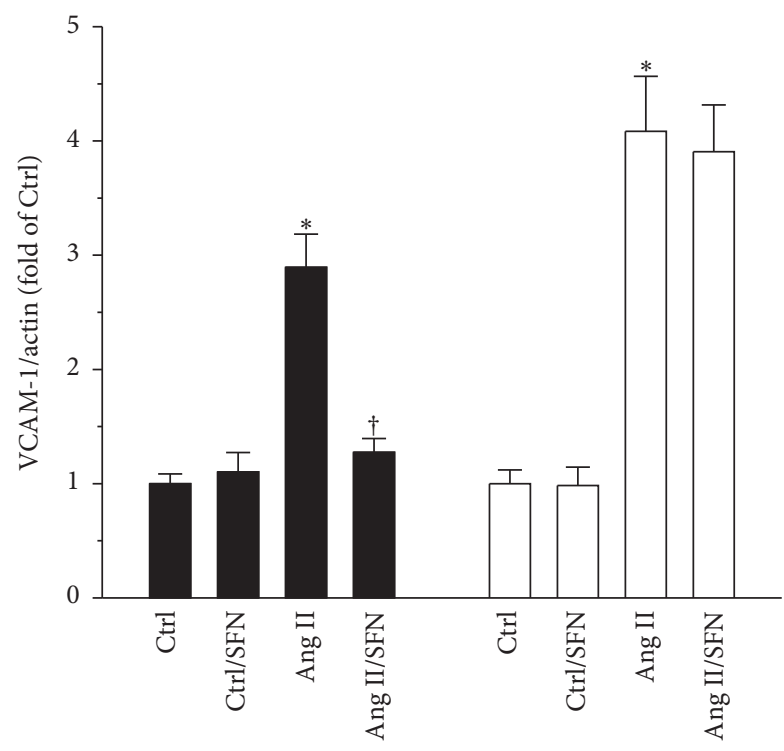

WT

$\square$ Nrf2-null

(b)

(a)

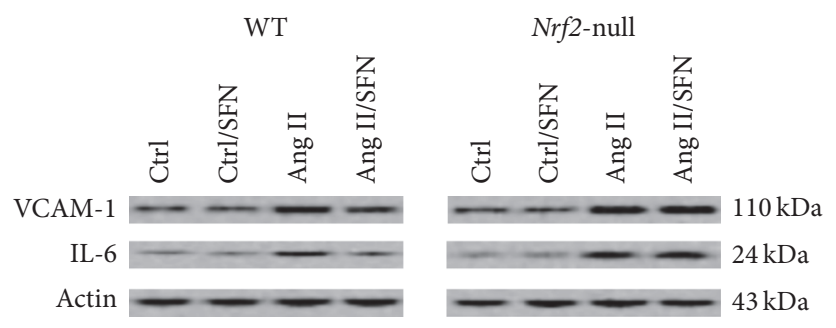

FIGURE 4: NRF2 was required for SFN amelioration of Ang II-induced testicular inflammation. Testicular inflammatory markers (a) IL-6 and (b) VCAM-1 were measured by Western blot. Data were normalised by respective Ctrl and presented as means $\pm \operatorname{SD}(n=5) .{ }^{*} p<0.05$ versus Ctrl; ${ }^{\dagger} p<0.05$ versus Ang II. 


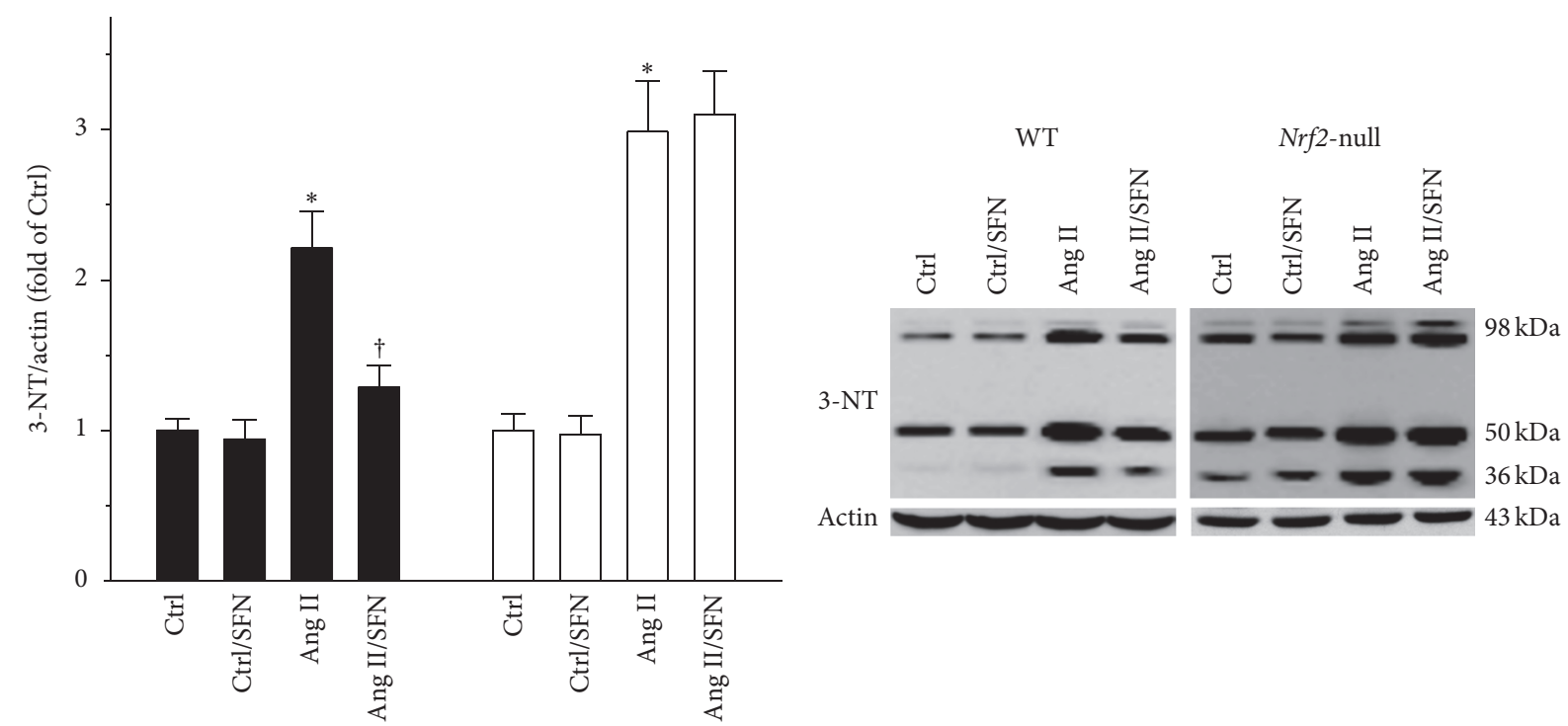

(a)

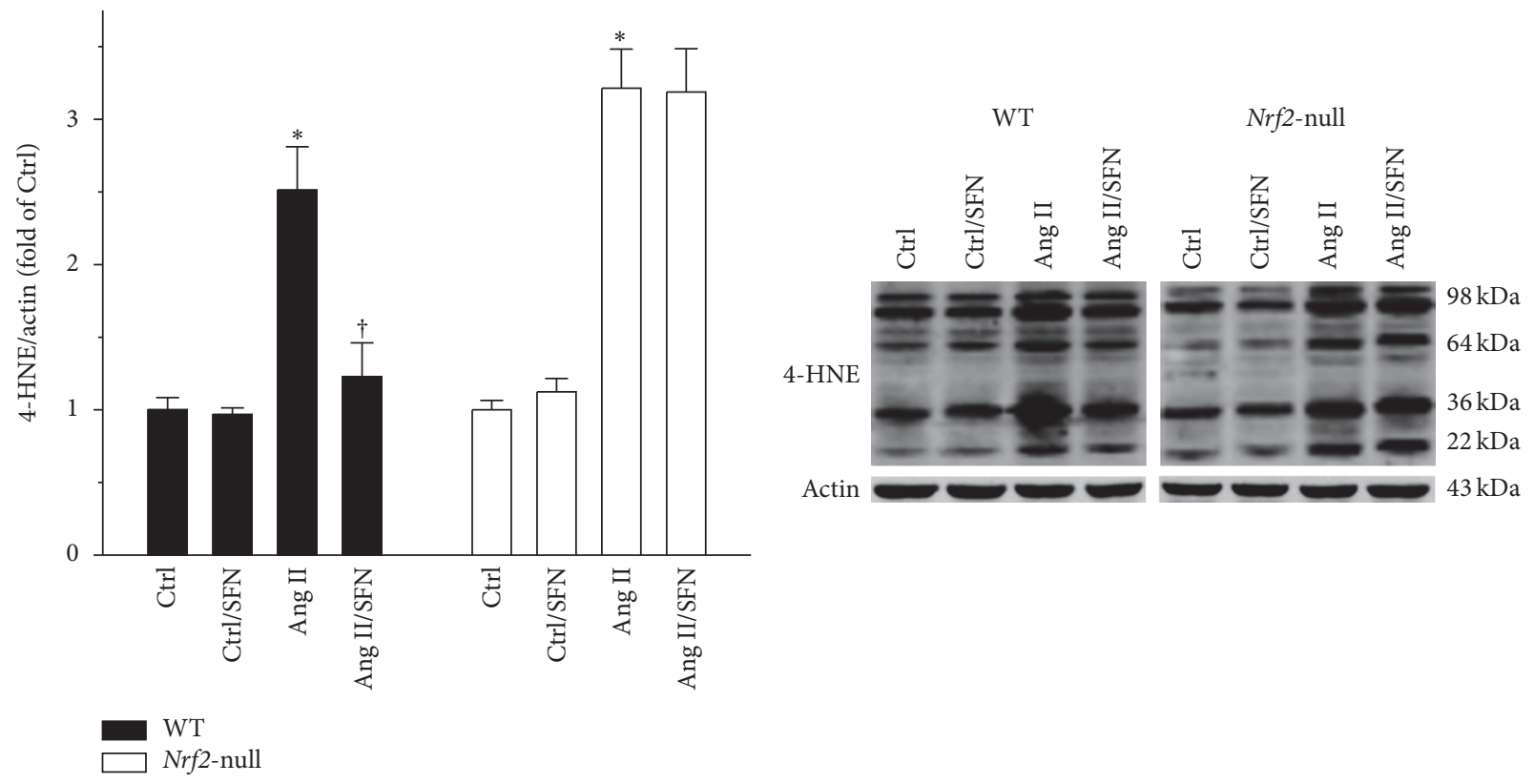

(b)

FIGURE 5: NRF2 played a key role in SFN protection against Ang II-induced testicular oxidative stress. The status of testicular oxidative damage was shown by measuring protein levels of (a) 3-NT and (b) 4-HNE. Data were normalised by respective Ctrl and presented as means $\pm \mathrm{SD}(n=5) .{ }^{*} p<0.05$ versus Ctrl; ${ }^{\dagger} p<0.05$ versus Ang II.

multiple sclerosis [48]. The possible reasons for the failure of bardoxolone methyl may be the application in an inappropriate stage of disease, the lack of specificity, and interactions between medicines $[49,50]$. Although SFN has been tested in many clinical trials [45], none of these was related to testicular diseases. Moreover, very few studies focused on the effect of SFN on testicular diseases in animal models. Thus, there remains an urgent need to test the effect of SFN on various models of testicular diseases, especially the ones with oxidative stress as the main mechanism.
In summary, the present study indicates, for the first time, that Ang II may exert a detrimental function in inducing testicular apoptotic cell death. Other findings suggest that $\mathrm{NRF} 2$ is required for SFN protection against Ang II-induced testicular injury.

\section{Abbreviations}

3-NT: 3-Nitrotyrosine 4-HNE: 4-Hydroxynonenal 


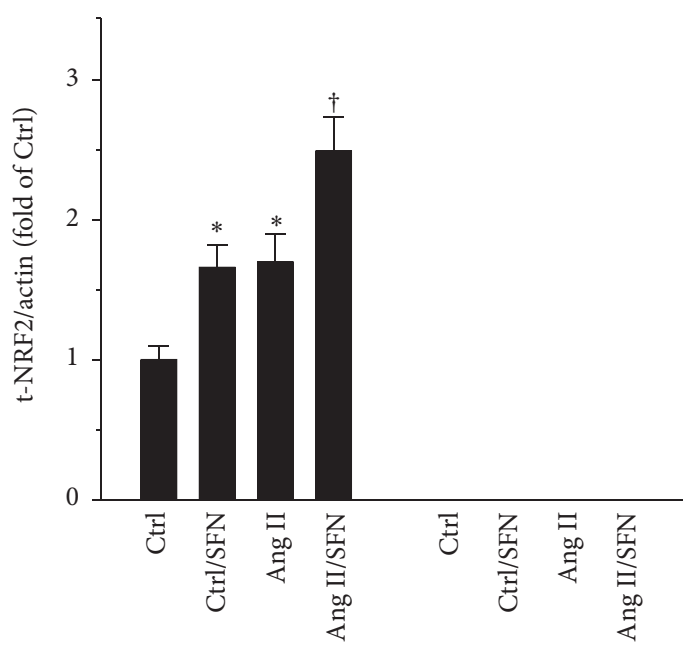

WT Nrf2-null

(a)

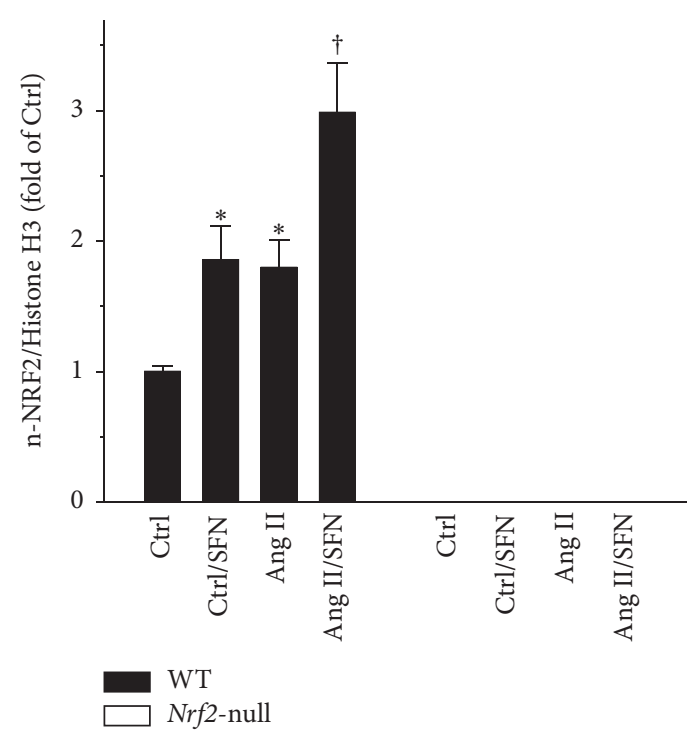

(b)
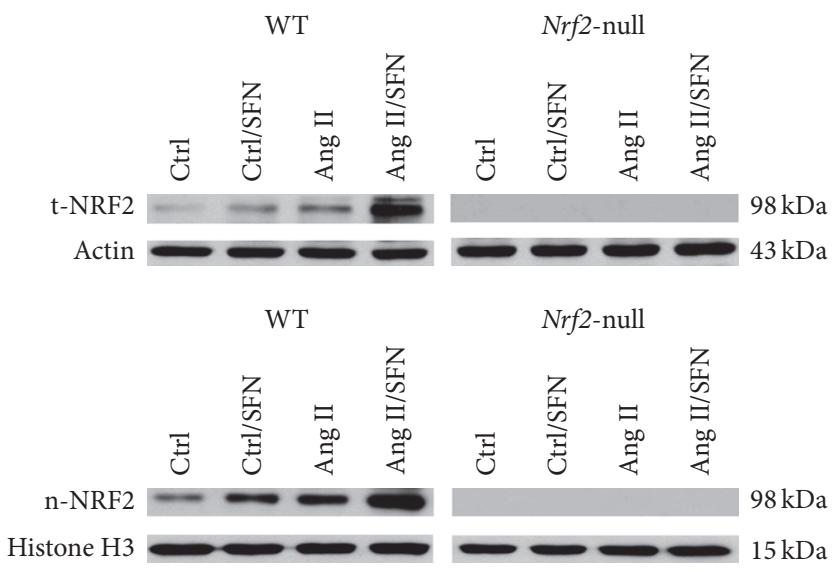

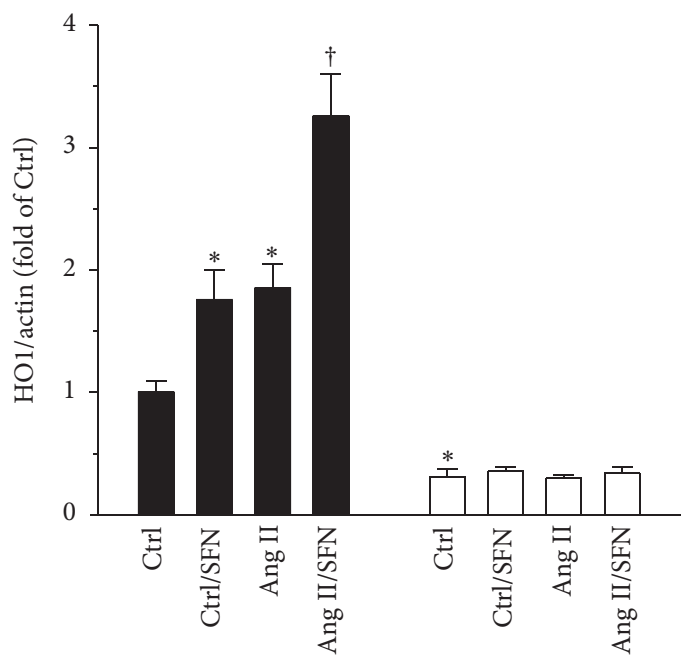

WT

Nrf2-null

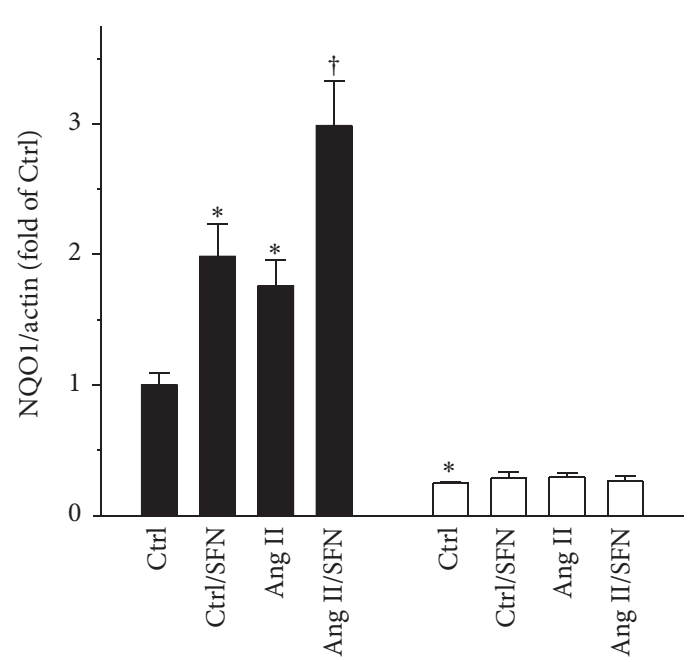

WT

Nrf2-null

(c)

(d)

FIGURE 6: Nrf2 gene deletion led to a complete loss of SFN function in activating testicular antioxidant gene transcription. Nrf2 gene expression and function were determined by measuring protein levels of (a) t-NRF2 and (b) n-NRF2, along with (c) Ho1 and (d) Nqo1 mRNAs. t-NRF2, total NRF2; n-NRF2, nuclear NRF2. Data were normalised by WT Ctrl and presented as means $\pm \operatorname{SD}(n=5) .{ }^{*} p<0.05$ versus Ctrl; ${ }^{\dagger} p<0.05$ versus Ang II. 


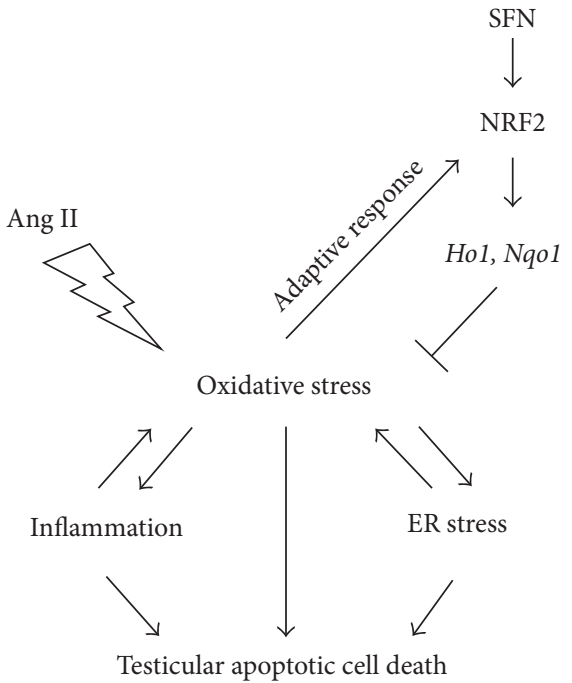

FIgURE 7: Possible mechanisms for SFN prevention of Ang II-induced testicular apoptotic cell death. Ang II-induced oxidative stress, inflammation, and ER stress contribute to testicular apoptotic cell death. The increased oxidative stress activated NRF2 and the transcription of its downstream target genes $\mathrm{Hol}$ and $\mathrm{Nqol}$, as an adaptive mechanism for defence. Ang II-induced testicular damage could further be alleviated by SFN, via the activation of the NRF2 antioxidant signalling.

\author{
Actin: $\quad \beta$-Actin \\ Ang II: Angiotensin II \\ ATF4: Activating transcription factor 4 \\ Bax: $\quad$ Bcl-2-associated $\mathrm{X}$ protein \\ Bcl-2: $\quad$ B-cell lymphoma 2 \\ BIP: $\quad$ Binding immunoglobulin protein \\ CHOP: C/EBP homologous protein \\ DTT: Dithiothreitol \\ ER: $\quad$ Endoplasmic reticulum \\ HO1: Heme oxygenase 1 \\ IL-6: Interleukin 6 \\ NRF2: Nuclear factor (erythroid-derived 2)-like 2 \\ NQO1: $\quad \mathrm{NAD}(\mathrm{P}) \mathrm{H}$ dehydrogenase (quinone 1) \\ SFN: $\quad$ Sulforaphane \\ TNF- $\alpha$ : Tumor necrosis factor- $\alpha$ \\ VCAM-1: Vascular cell adhesion molecule-1 \\ WT: Wild type.
}

\section{Competing Interests}

The authors declare that there is no conflict of interests associated with this article.

\section{Acknowledgments}

This work was supported in part by the Natural Science Foundation of Jilin Province (20160101117JC and CZZR2014021) to Yonggang Wang; the Norman Bethune Program of Jilin University (2015438) and the National Natural Science Foundation of China (81600573) to Hao Wu; and the National Institutes of Health grant (1R01DK 091338-01A1) to Lu Cai.

\section{References}

[1] M. Chehab, A. Madala, and J. C. Trussell, "On-label and offlabel drugs used in the treatment of male infertility," Fertility and Sterility, vol. 103, no. 3, pp. 595-604, 2015.
[2] A. B. Atkinson, J. J. Brown, R. Fraser et al., "Angiotensin II and renal hypertension in dog, rat and man: effect of converting enzyme inhibition," Clinical and Experimental Hypertension, vol. 2, no. 3-4, pp. 499-524, 1980.

[3] J. T. Fitzsimons, "Angiotensin II in the control of hypovolaemic thirst and sodium appetite," Canadian Journal of Physiology and Pharmacology, vol. 58, no. 5, pp. 441-444, 1980.

[4] T. Kono, F. Ikeda, F. Oseko, H. Imura, S. Shimbo, and J. Endo, "Angiotensin II analogue and essential hypertension," Nippon Rinsho, vol. 37, no. 10, pp. 3503-3510, 1979.

[5] M. Gianzo, I. Muñoa-Hoyos, I. Urizar-Arenaza et al., "Angiotensin II type 2 receptor is expressed in human sperm cells and is involved in sperm motility," Fertility and Sterility, vol. 105, no. 3, pp. 608-616, 2016.

[6] F. Rossi, A. Ferraresi, P. Romagni, L. Silvestroni, and V. Santiemma, "Angiotensin II stimulates contraction and growth of testicular peritubular myoid cells in vitro," Endocrinology, vol. 143, no. 8, pp. 3096-3104, 2002.

[7] H. Welter, A. Huber, S. Lauf et al., "Angiotensin II regulates testicular peritubular cell function via AT1 receptor: a specific situation in male infertility," Molecular and Cellular Endocrinology, vol. 393, no. 1-2, pp. 171-178, 2014.

[8] S. I. Dikalov, R. R. Nazarewicz, A. Bikineyeva et al., "Nox2-induced production of mitochondrial superoxide in angiotensin II-mediated endothelial oxidative stress and hypertension," Antioxidants and Redox Signaling, vol. 20, no. 2, pp. 281-294, 2014.

[9] S. Kossmann, H. Hu, S. Steven et al., "Inflammatory monocytes determine endothelial nitric-oxide synthase uncoupling and nitro-oxidative stress induced by Angiotensin II," Journal of Biological Chemistry, vol. 289, no. 40, pp. 27540-27550, 2014.

[10] Y. Tan, X. Li, S. D. Prabhu et al., "Angiotensin II plays a critical role in alcohol-induced cardiac nitrative damage, cell death, remodeling, and cardiomyopathy in a protein kinase c/nicotinamide adenine dinucleotide phosphate oxidase-dependent manner," Journal of the American College of Cardiology, vol. 59, no. 16, pp. 1477-1486, 2012. 
[11] J. Yang, Y. Tan, F. Zhao et al., "Angiotensin II plays a critical role in diabetic pulmonary fibrosis most likely via activation of NADPH oxidase-mediated nitrosative damage," American Journal of Physiology_Endocrinology and Metabolism, vol. 301, no. 1, pp. E132-E144, 2011.

[12] N. Kaushal and M. P. Bansal, "Selenium variation induced oxidative stress regulates p53 dependent germ cell apoptosis: plausible involvement of HSP70-2," European Journal of Nutrition, vol. 48, no. 4, pp. 221-227, 2009.

[13] M. Muratori, L. Tamburrino, S. Marchiani et al., "Investigation on the origin of sperm DNA fragmentation: role of apoptosis, immaturity and oxidative stress," Molecular Medicine, vol. 21, pp. 109-122, 2015.

[14] K. Shiraishi, H. Takihara, and H. Matsuyama, "Elevated scrotal temperature, but not varicocele grade, reflects testicular oxidative stress-mediated apoptosis," World Journal of Urology, vol. 28, no. 3, pp. 359-364, 2010.

[15] Y. Song, Y. Shi, H. Yu, Y. Hu, Y. Wang, and K. Yang, "P,p'Dichlorodiphenoxydichloroethylene induced apoptosis of Sertoli cells through oxidative stress-mediated p38 MAPK and mitochondrial pathway," Toxicology Letters, vol. 202, no. 1, pp. 55-60, 2011.

[16] Y.-C. Yeh, T.-J. Liu, L.-C. Wang et al., "A standardized extract of Ginkgo biloba suppresses doxorubicin-induced oxidative stress and p53-mediated mitochondrial apoptosis in rat testes," British Journal of Pharmacology, vol. 156, no. 1, pp. 48-61, 2009.

[17] B. Chhunchha, N. Fatma, E. Kubo, P. Rai, S. P. Singh, and D. P. Singh, "Curcumin abates hypoxia-induced oxidative stress based-ER stress-mediated cell death in mouse hippocampal cells (HT22) by controlling Prdx6 and NF- $\kappa$ B regulation," American Journal of Physiology-Cell Physiology, vol. 304, no. 7, pp. C636-C655, 2013.

[18] C. W. Younce and P. E. Kolattukudy, "MCP-1 causes cardiomyoblast death via autophagy resulting from ER stress caused by oxidative stress generated by inducing a novel zinc-finger protein, MCPIP," Biochemical Journal, vol. 426, no. 1, pp. 43-53, 2010.

[19] Y. Gong, J. Wu, Y. Huang, S. Shen, and X. Han, "Nonylphenol induces apoptosis in rat testicular Sertoli cells via endoplasmic reticulum stress," Toxicology Letters, vol. 186, no. 2, pp. 84-95, 2009.

[20] Y.-L. Ji, H. Wang, C. Zhang et al., "N-acetylcysteine protects against cadmium-induced germ cell apoptosis by inhibiting endoplasmic reticulum stress in testes," Asian Journal of Andrology, vol. 15, no. 2, pp. 290-296, 2013.

[21] Y.-L. Ji, H. Wang, X.-F. Zhao et al., "Crosstalk between endoplasmic reticulum stress and mitochondrial pathway mediates cadmium-induced germ cell apoptosis in testes," Toxicological Sciences, vol. 124, no. 2, pp. 446-459, 2011.

[22] P. Lin, F. Chen, J. Sun et al., "Mycotoxin zearalenone induces apoptosis in mouse Leydig cells via an endoplasmic reticulum stress-dependent signalling pathway," Reproductive Toxicology, vol. 52, pp. 71-77, 2015.

[23] S.-J. Park, T.-S. Kim, C.-K. Park et al., "hCG-induced endoplasmic reticulum stress triggers apoptosis and reduces steroidogenic enzyme expression through activating transcription factor 6 in Leydig cells of the testis," Journal of Molecular Endocrinology, vol. 50, no. 2, pp. 151-166, 2013.

[24] A. Dandekar, R. Mendez, and K. Zhang, "Cross talk between ER stress, oxidative stress, and inflammation in health and disease," Methods in Molecular Biology, vol. 1292, pp. 205-214, 2015.
[25] H. Kaneto, "Oxidative stress and ER stress in diabetes," Japanese Journal of Clinical Medicine, vol. 69, supplement 1, pp. 171-175, 2011.

[26] T. Jiang, Z. Huang, Y. Lin, Z. Zhang, D. Fang, and D. D. Zhang, "The protective role of Nrf2 in streptozotocin-induced diabetic nephropathy," Diabetes, vol. 59, no. 4, pp. 850-860, 2010.

[27] T. Nguyen, P. J. Sherratt, and C. B. Pickett, "Regulatory mechanisms controlling gene expression mediated by the antioxidant response element," Annual Review of Pharmacology and Toxicology, vol. 43, pp. 233-260, 2003.

[28] W. Dong, Y. Jia, X. Liu et al., "Sodium butyrate activates NRF2 to ameliorate diabetic nephropathy possibly via inhibition of HDAC," Journal of Endocrinology, vol. 232, no. 1, pp. 71-83, 2017.

[29] B. N. Nakamura, G. Lawson, J. Y. Chan et al., "Knockout of the transcription factor NRF2 disrupts spermatogenesis in an agedependent manner," Free Radical Biology and Medicine, vol. 49, no. 9, pp. 1368-1379, 2010.

[30] H. Zheng, S. A. Whitman, W. Wu et al., “Therapeutic potential of Nrf2 activators in streptozotocin-induced diabetic nephropathy," Diabetes, vol. 60, no. 11, pp. 3055-3066, 2011.

[31] H. Wu, L. Kong, Y. Cheng et al., "Metallothionein plays a prominent role in the prevention of diabetic nephropathy by sulforaphane via up-regulation of Nrf2," Free Radical Biology \& Medicine, vol. 89, pp. 431-442, 2015.

[32] Y. Wang, Z. Zhang, W. Guo et al., "Sulforaphane reduction of testicular apoptotic cell death in diabetic mice is associated with the upregulation of Nrf2 expression and function," American Journal of Physiology_Endocrinology and Metabolism, vol. 307, no. 1, pp. E14-E23, 2014.

[33] Y. Bai, W. Cui, Y. Xin et al., "Prevention by sulforaphane of diabetic cardiomyopathy is associated with up-regulation of Nrf2 expression and transcription activation," Journal of Molecular and Cellular Cardiology, vol. 57, no. 1, pp. 82-95, 2013.

[34] Q. Liu, G. Wang, G. Zhou et al., "Angiotensin II-induced p53-dependent cardiac apoptotic cell death: its prevention by metallothionein," Toxicology Letters, vol. 191, no. 2-3, pp. 314320, 2009.

[35] G. Zhou, X. Li, D. W. Hein et al., "Metallothionein suppresses angiotensin II-induced nicotinamide adenine dinucleotide phosphate oxidase activation, nitrosative stress, apoptosis, and pathological remodeling in the diabetic heart," Journal of the American College of Cardiology, vol. 52, no. 8, pp. 655-666, 2008.

[36] N. Ben Halima, A. Ben Slima, I. Moalla et al., "Protective effects of oat oil on deltamethrin-induced reprotoxicity in male mice," Food and Function, vol. 5, no. 9, pp. 2070-2077, 2014.

[37] A. T. Farag, A. H. Radwan, M. H. Eweidah, R. H. Elmazoudy, and A. E.-K. El-Sebae, "Evaluation of male-mediated reproductive toxic effects of methamidophos in the mouse," Andrologia, vol. 44, no. 2, pp. 116-124, 2012.

[38] L. Cai, J. Wang, Y. Li et al., "Inhibition of superoxide generation and associated nitrosative damage is involved in metallothionein prevention of diabetic cardiomyopathy," Diabetes, vol. 54, no. 6, pp. 1829-1837, 2005.

[39] Y. Wang, W. Feng, W. Xue et al., "Inactivation of GSK-3 $\beta$ by metallothionein prevents diabetes-related changes in cardiac energy metabolism, inflammation, nitrosative damage, and remodeling," Diabetes, vol. 58, no. 6, pp. 1391-1402, 2009.

[40] H. Wu, S. Zhou, L. Kong et al., "Metallothionein deletion exacerbates intermittent hypoxia-induced renal injury in mice," Toxicology Letters, vol. 232, no. 2, pp. 340-348, 2015. 
[41] H. Wu, L. Kong, Y. Tan et al., "C66 ameliorates diabetic nephropathy in mice by both upregulating NRF2 function via increase in miR-200a and inhibiting miR-21," Diabetologia, vol. 59, no. 7, pp. 1558-1568, 2016.

[42] A. Azenabor, A. O. Ekun, and O. Akinloye, "Impact of inflammation on male reproductive tract," Journal of Reproduction and Infertility, vol. 16, no. 3, pp. 123-129, 2015.

[43] E. J. Calabrese, G. Dhawan, R. Kapoor, I. Iavicoli, and V. Calabrese, "HORMESIS: a fundamental concept with widespread biological and biomedical applications," Gerontology, vol. 62, no. 5, pp. 530-535, 2015.

[44] E. J. Calabrese, "Hormesis: changing view of the dose-response, a personal account of the history and current status," Mutation Research - Reviews in Mutation Research, vol. 511, no. 3, pp. 181$189,2002$.

[45] C. A. Houghton, R. G. Fassett, and J. S. Coombes, "Sulforaphane: translational research from laboratory bench to clinic," Nutrition Reviews, vol. 71, no. 11, pp. 709-726, 2013.

[46] P. E. Pergola, M. Krauth, J. W. Huff et al., "Effect of bardoxolone methyl on kidney function in patients with T2D and stage $3 \mathrm{~b}-4$ CKD," American Journal of Nephrology, vol. 33, no. 5, pp. 469476, 2011.

[47] E. T. Hall and V. Bhalla, "Is there a sweet spot for nrf2 activation in the treatment of diabetic kidney disease?" Diabetes, vol. 63, no. 9, pp. 2904-2905, 2014.

[48] R. Gold, L. Kappos, D. L. Arnold et al., "Placebo-controlled phase 3 study of oral BG-12 for relapsing multiple sclerosis," New England Journal of Medicine, vol. 367, pp. 1098-1107, 2012.

[49] D. H. Ellison, "Bardoxolone methyl in type 2 diabetes and advanced chronic kidney disease," New England Journal of Medicine, vol. 370, no. 18, pp. 1768-1769, 2014.

[50] D. D. Zhang, "Bardoxolone brings Nrf2-based therapies to light," Antioxidants and Redox Signaling, vol. 19, no. 5, pp. 517518, 2013. 


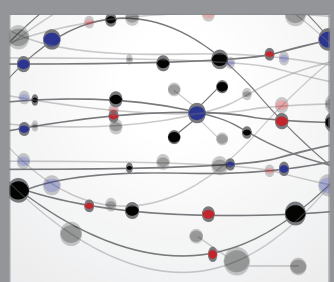

The Scientific World Journal
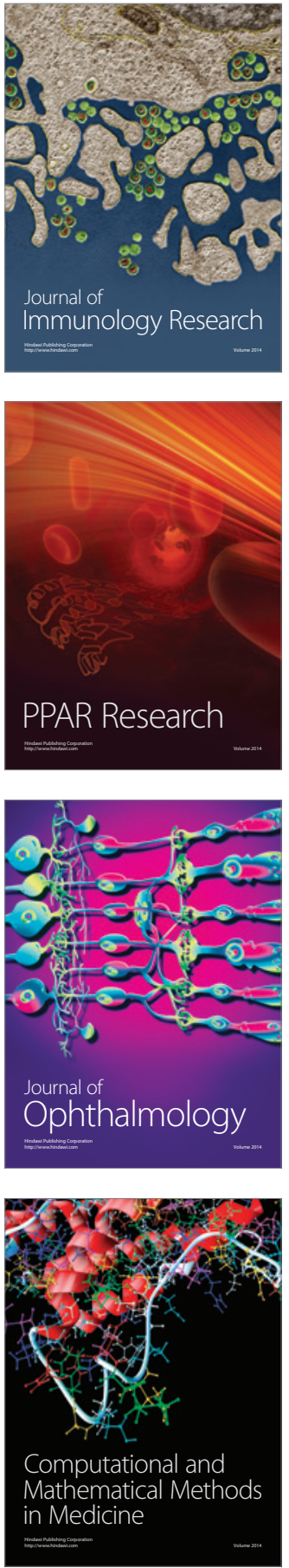

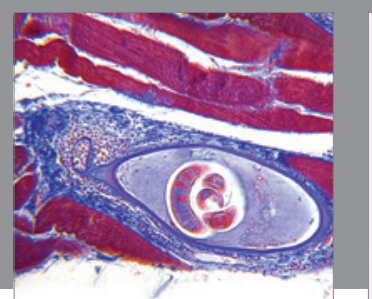

Gastroenterology Research and Practice
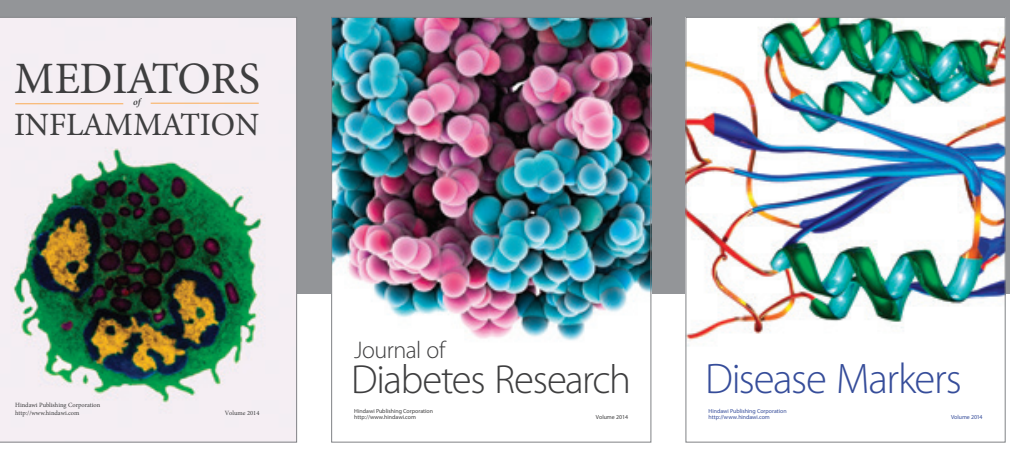

Disease Markers

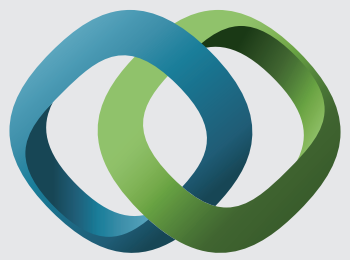

\section{Hindawi}

Submit your manuscripts at

https://www.hindawi.com
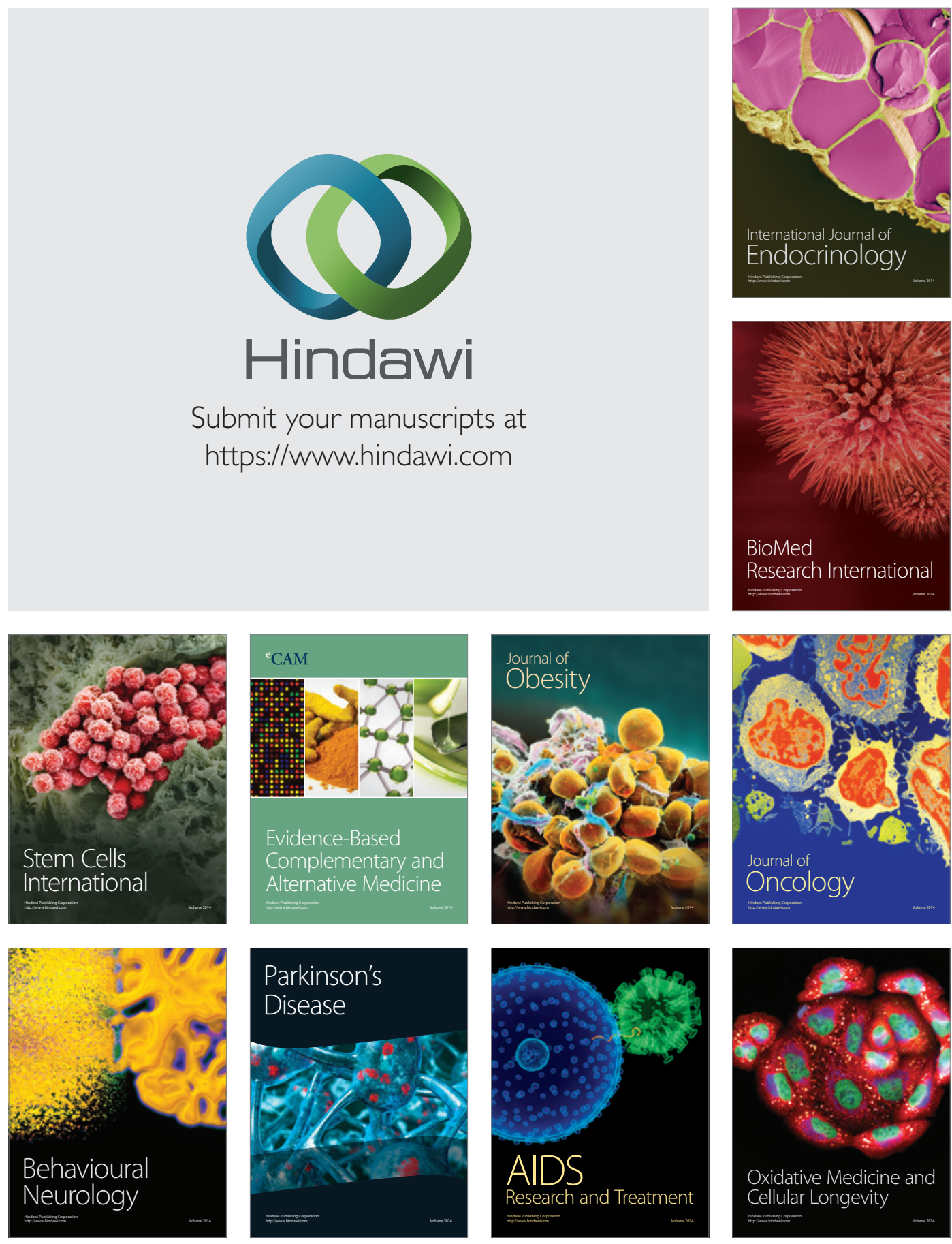